\title{
Modifying geopolymer wettability by plasma treatment and fly ash
}

\author{
Vojtěch Růžek ${ }^{1 *}$, Petr Louda ${ }^{1}$, Katarzyna Buczkowska ${ }^{1,2}$, Just Paweł ${ }^{2}$, Prałat Karol ${ }^{3}$, Ciemnicka Justyna ${ }^{3}$, Plaskota \\ Przemysław ${ }^{4}$
}

\author{
Department of Material Science, Faculty of Mechanical Engineering, Technical University of Liberec \\ Studenstká 2, 46117 Liberec, Czech Republic; vojtech.ruzek@tul.cz (V.R); petr.louda@tul.cz (P.L); \\ katarzyna.ewa.buczkowska@tul.cz (K.B) \\ 2. Department of Materials Technology and Production Systems, Faculty of Mechanical Engineering, Lodz \\ University of Technology, Stefanowskiego 1/15, Lodz, Poland pawel.just@p.lodz.pl (P.J.) \\ 3. Faculty of Civil Engineering, Mechanics and Petrochemistry, Warsaw University of Technology, \\ Łukasiewicza 17, \\ 09-400 Płock, Poland, Karol.Pralat@pw.edu.pl justyna.ciemnicka@pw.edu.pl (J.C.) \\ 4. Department of Acoustics, Multimedia and Signal Processing, Wroclaw University of Science and Tech- \\ nology, wybrzeże Stanisława Wyspiańskiego 27, 50-370 Wrocław, ul. Z. Łukasiewicza 17, 04-900 Płock, \\ Poland; przemyslaw.plaskota@pwr.edu.pl (P.P) \\ * Correspondence: vojtech.ruzek@tul.cz; Tel.: +420724017256
}

\begin{abstract}
This paper deals with investigation of changes in geopolymer wettability with increasing mass fraction of high-carbon fly ash and surface treatment by cold atmospheric plasma (CAP). In this study, multiple samples of geopolymers were prepared, including those with $5 \%$ and $10 \%$ of high-carbon fly ash from coal-fired power station. Wettability of samples was then measured before and after plasma treatment, both on surface and cut surface. While addition of fly ash only had low effect on the wettability, as in most cases, it only lowered the initial contact angle without speeding up the speed of soaking for compact geopolymer and actually slowed the soaking for foamed geopolymer, plasma treatment had significant impact and made the geopolymer hydrophobic.
\end{abstract}

Keywords: geopolymer; plasma; surface treatment; fly ash; wettability

\section{Introduction}

Geopolymers are materials formed by polycondensation of aluminosilicate materials, such as metakaolin or fly ash, in strongly basic environment, usually in hydroxide or silicate solution. During the reaction, aluminosilicates are transformed to polysialates and form zeolitic (microporous) structure. In comparsion with Ordinary Portland cement (OPC), most widely used construction material, geopolymers exhibit higher compressive strength, resistance against high temperatures and chemicals and lower thermal conductivity. Their manufacturing also requires less energy than OPC. The disadvantages include lower tensile strength and higher price. They may also be used for deposition of waste, such as high-carbon fly ash from coal power stations or glass. This kind of waste may also serve as coloring, unless they have a detrimental effect on properties of geopolymer. Using such commodities as a geopolymer filler may also lower the price or geopolymers and lower the amount of landfilled waste. Geopolymers are a potential alternative to OPC as a building material, as well as useful materal for other special application where their properties may be used, such as passive fire protection, where foamed geopolymer is used, as foaming decreases its thermal conductivity and weight, or as insulation for buildings. Geopolymers are also a viable material for 3D printing,[1-2][27-37] 
Geopolymers, as well as OPC, are also commonly reinforced by various types of fibers, to compensate for their low tensile and flexural strength, although some materials, such as common glass or light metals cannot be used, due to high geopolymer basicity. Fibers also reduce internal cracking. Materials usable to reinforce geopolymers (and other materials) include carbon, basalt, steel, microspheres, various polymers etc. Geopolymers may also be reinforced with biological materials, such as flax or hemp fibers., or waste materials (such as glass wool) [12-26]

Plasma, an ionized gas exhibiting kvasineutrality and colletive behavior, is used for cleaning, etching and activation of surfaces, thin layer formation and other purposes. Unlike other methods, it doesn't require high temperatures and agressive or toxic chemicals (solvents or catalysts), and can therefore be used for less durable materials or in medicine. [3-5]

When used to activate a surface to increase its wettability, reactivity etc., plasma may change the chemical properties of the surface by depositing functional groups, such as hydroxil, or changing composition of the surface layer. Plasma may also change the surface morphology by the process of plasma etching, which increases coarseness and surface area. If the surface is contaminated, plasma may also be used to clean it. Plasma treatments are one of the most widely used methods of surface hydrophilization, being universal and efficient, while doing no to minimal damage to the surface, especially when compared to treatments using chemicals, such as acids, and leaving no toxic residue. This makes plasma pretreatment a viable method of improving the properties of materials used for medicine, such as scaffolds or implants. [2][6-7][38-39]

As geopolymers may be used as an alternative to OPC, they may also be coated or modified with various types of coatings, including penetration coatings, hydrophobization coatings, antimicrobial coatings etc. However, these coatings, especially when used on industrial scale, may require the geopolymer surface to be hydrophilic and wettable, so that optimal spread and adhesion of the coating is ensured. Geopolymers may also form variable surfaces, depending on their composition, geopolymerization time etc. and may not always be completely wettable. This study therefore aims to investigate the wettability of various types of geopolymers, including those with high-carbon fly ash additive (as using geopolymers to encapsulate the fly ash is a potential viable method to dispose of it, but the ash might have negative impact on geopolymer properties), and the influence of CAP (cold atmospheric plasma) treatment on their wettability, to determine the possibility of using CAP to activate geopolymer surface for the purpose of further functionalization by varnishes, chemical treatments etc. A commercial waterproofing varnish was also tested the possibility of waterproofing various geopolymer materials. [12][40-41]

\section{Materials and Methods}




\subsection{Materials used}

Baucis LNa, component A (cement) and B (liquid activator), České lupkové závody a.s Baucis Lk component A (cement) and B (liquid activator), České lupkové závody a.s Quartz sand, Sklopísek Střeleč

Silica fumes RW-Füller, AMG Silicon

Aluminium powder AIPRA, PK Chemie

Basalt fibers (length $6 \mathrm{~mm}$, width $13 \mu \mathrm{m}$ ) - ORLIMEX CZ, s.r.o.

Revacryl UF 4210 varnish, Synthomer

Fly ash - Polska Grupa Energetyczna

\subsection{Fly ash}

High-carbon fly ash, used as a geopolymer additive, was produced by PGE Polska Grupa Energetyczna and comes from an electrostatic precipitator of a coal-fired power station. According to analysis performed at TUL, it contains 76,89 wt. \% of Carbon in graphite form. It also contains oxygen, iron, calcium and other elements (presumably in oxide form). Its elemental composition is shown in Table 1.

Table 1. Fly ash composition

\begin{tabular}{cc}
\hline Element & $\mathbf{W t} \%$ \\
\hline $\mathrm{C}$ & 76.89 \\
$\mathrm{O}$ & 7.10 \\
$\mathrm{Fe}$ & 5.16 \\
$\mathrm{Ca}$ & 4.75 \\
$\mathrm{Si}$ & 1.38 \\
$\mathrm{~S}$ & 1.35 \\
$\mathrm{Al}$ & 1.02 \\
$\mathrm{Mg}$ & 0.88 \\
$\mathrm{Cl}$ & 0.53 \\
$\mathrm{~W}$ & 0.25 \\
$\mathrm{~K}$ & 0.16 \\
$\mathrm{Na}$ & 0.11 \\
$\mathrm{P}$ & 0.1 \\
\hline
\end{tabular}

\subsection{Geopolymer samples}

Geopolymer samples were prepared from sodium metakaolin based geopolymer Baucis LNa and its water glass and sodium hydroxide based activator, both manufactured by České lupkové Závody a.s [8]. Quartz sand and silica fumes were added to all samples (in accordance with geopolymer recipe used at TUL for research), while the samples differed by other additives. From each set, both compact and foamed samples were prepared, with aluminium powder serving as foaming agent. The base composition of samples without additives is shown in Table 2. In total, 5 sets of samples were prepared.

Table 1. Geopolymer base ingredients

Material Weight (g)




\begin{tabular}{cc} 
Geopolymer base & 1000 \\
Activator & 900 \\
Sand & 1000 \\
Silica & 50 \\
Aluminium (for foamed) & 15 \\
\hline
\end{tabular}

First set: Additional $70 \mathrm{~g}$ of basalt fibers.

Second set: Only the base ingredients.

Third set: $5 \mathrm{wt}$ \% of high-carbon fly ash.

Fourth set: 10 wt. \% of high carbon fly ash.

Fifth set: Base set of ingredients, potassium base used instead of sodium.

\subsection{Sample preparation}

After mixing the ingredients of each set, the paste was mixed for 5 minutes, for foamed samples, aluminium powder was also added after mixing and the paste was mixed for an additional minute, after which it was poured into wooden (for experiments) or plastic (for display) molds, wrapped with polyvinil sheet and left for 1 day. The samples were then cured at $45^{\circ} \mathrm{C}$ for 5 hours, unwrapped and cured at $82^{\circ} \mathrm{C}$ for additional 15 hours. Samples were then cut to smaller pieces suitable for testing, cleaned with water and dried at $45^{\circ} \mathrm{C}$ for 5 hours. All tests were performed on both the uncut surface of geopolymer and on the cut surface. Addition of high-carbon fly ash colored geopolymers into shades of dark grey, as seen in Figure 1. Geopolymer made from potassium base foamed more significantly with the addition of aluminium powder. The difference can be seen in Fig. 2

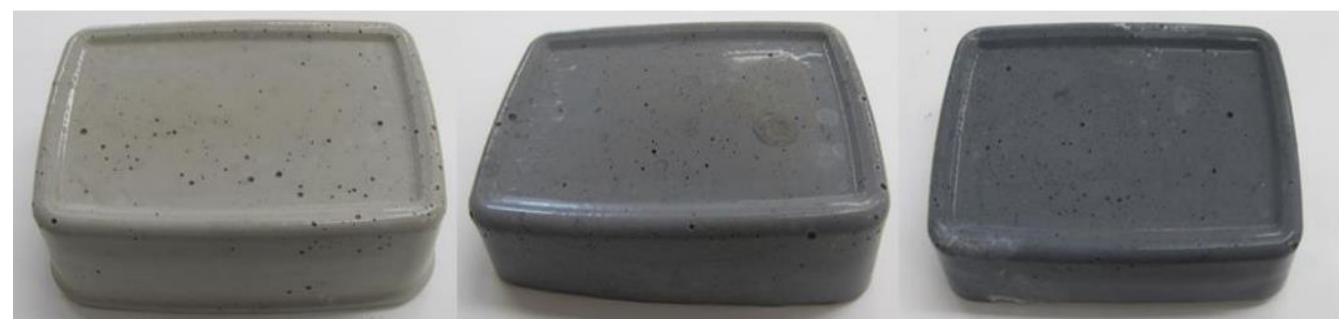

Figure 1. Geopolymers with $0 w t . \%, 5 w t . \%$ and $10 w t . \%$ of high-carbon fly ash

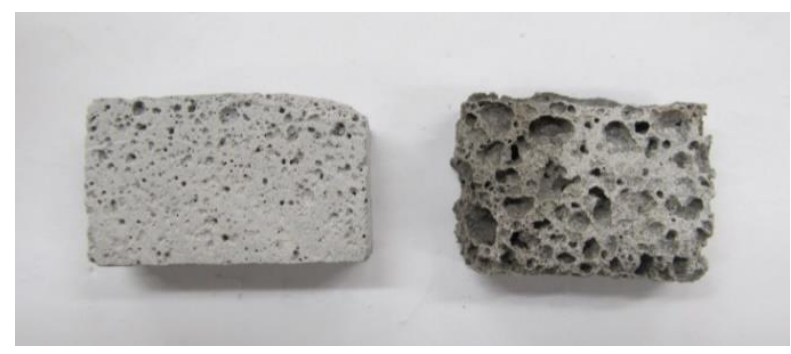

Figure 2. Foamed sodium (left) and potassium (right) geopolymer

\subsection{Plasma pretreatment}

For the purpose of testing plasma activation of geopolymer surface, samples were treated with Piezobrush PZ2, a device generating plasma from atmosphere using piezoelectric direct discharge device Ceraplas, which produces cold atmospheric-pressure a plasma jet from atmosphere (nitrogen-oxygen plasma) with temperature below $50^{\circ} \mathrm{C}$ and operating frequency of $50 \mathrm{kHz}$ (RF equivalent). Its maximum output energy is $10 \mathrm{~W}$. The device was fitted with near-field nozzle used for 
conductive surfaces, as using the standard nozzle caused visible discharges into the surface of geopolymer. [11]

The geopolymer surfaces were first cleared with textile and treated by cold atmospheric plasma jet for 5 seconds, while the surface was treated like this for two times, to ensure consistent surface activation. The distance between Piezobrush and sample was around $1 \mathrm{~mm}$ or below during surface treatment, as the near-field nozzle does not produce plasma unless in close proximity of the sample.

\subsection{Waterproofing varnish application}

Commercially available Revacryl UF 4210, a waterproofing varnish for mineral surfaces, was used to waterproof geopolymer samples. The varnish was applied by a paintbrush and multiple layers were applied to ensure optimal surface coverage and to prevent the geopolymer from penetrating the surface. Samples from all sets and both cut and uncut surfaces were waterproofed. [41]

\subsection{Wettability testing}

All wettability tests were performed on Surface Energy Evaluation System, a device used to measure the contact angle of a droplet of liquid. In this study, 3,5 $\mu$ l were used for each measurement. For all samples, the contact angle was measured 3 times during each measurement and mean value was used for calculation. The interval between measurements and number of measurements taken differed for each surface modification or type of surface (uncut or cut). Contact angle was measured at $t=0$ as well. The speed of water soaking into the surface was approximated as a change in contact angle in time.

For untreated and uncut surface, the measurement took 2 minutes with 20 seconds intervals.

For surface, both cut and uncut, treated with varnish, the measurement took 7 minutes with 1 minute intervals.

For cut surface and both cut and uncut surface treated with plasma, the interval was 1 second and contact angle was measured until the droplet soaked into the geopolymer.

\section{Results}

\subsection{Influence of fly ash and basalt fibers on wettability}

As seen in Fig. 3, addition of basalt fibers in compact geopolymer only marginally quickened soaking of water into the geopolymer,with the change of initial contact angle being marginable and within the error margin. However, as seen in Fig. 4, foaming the geopolymer with basalt fibers caused it to retain the wettability of a compact sample, with even slower soaking of water into its surface and similar initial contact angle. Without fibers, however, the geopolymer became more wettable, with nearly 3 times faster soaking and lower initial contact angle. Unlike the compact samples or foamed sample with basalt fibers, the droplet had also soaked into the sample completely before reaching 100s during some measurements. 


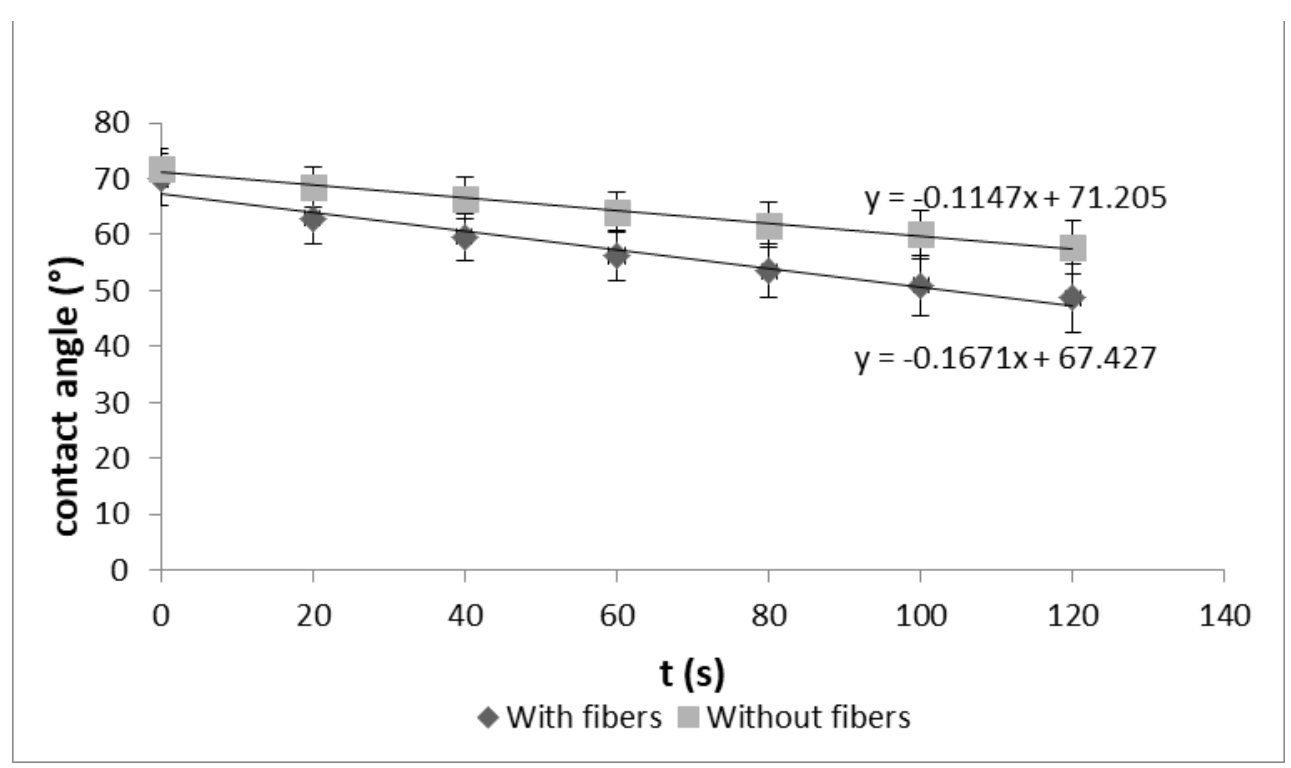

Figure 3. Wettability of compact geopolymer with and without basalt fibers

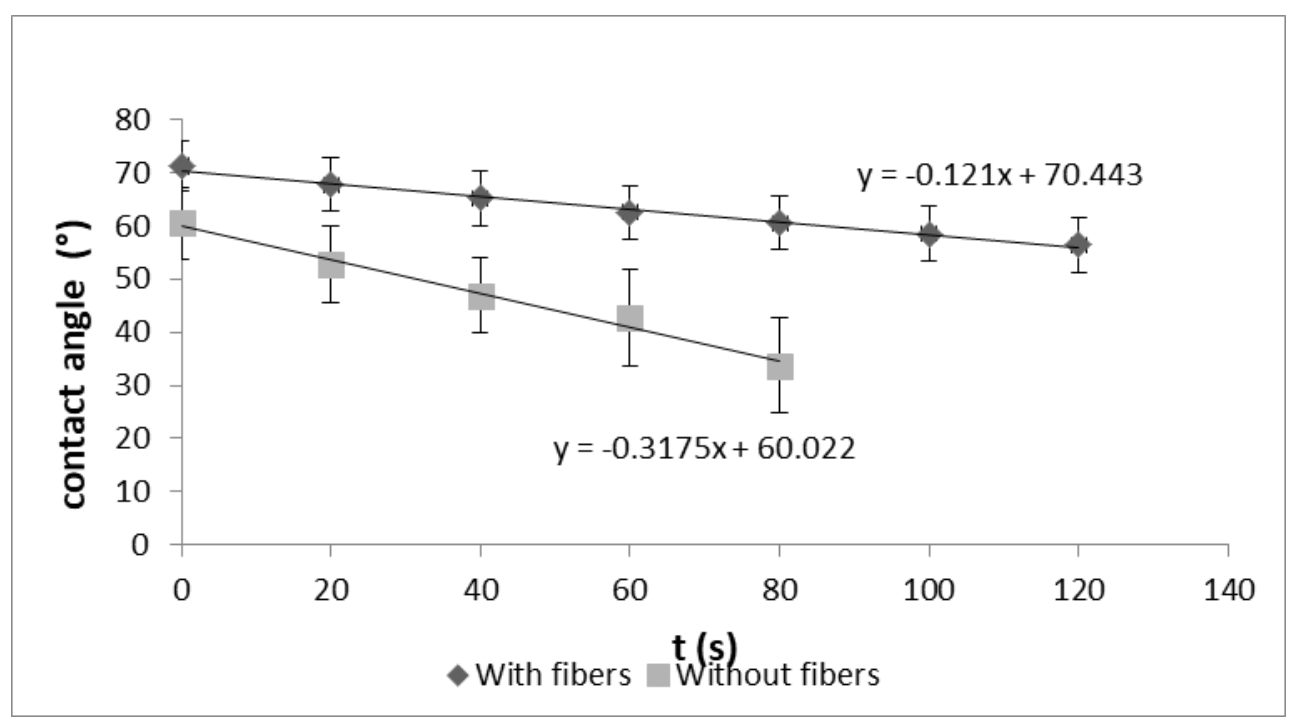

Figure 4. Wettability of foamed geopolymer with and without basalt fibers

As seen in Fig. 5, adding high-carbon fly ash into the compact geopolymer mix significantly lowered the initial contact angle, but did not speed up soaking of water into the geopolymer. At $5 \mathrm{wt}$ \%, the speed of soaking is nearly identical to the sample with no fly ash. At $10 \mathrm{wt}$. \%, the speed of soaking seemed to be marginally bigger. However, as seen in the graph, the difference is within the margin of error of both sets of measurements and may not exist at all. For the foamed samples, as seen in Fig. 6, adding fly ash, despite lowering the initial contact angle, slowed down soaking of water into the samples, although higher mass fraction of fly caused faster soaking than the smaller mass fraction. 


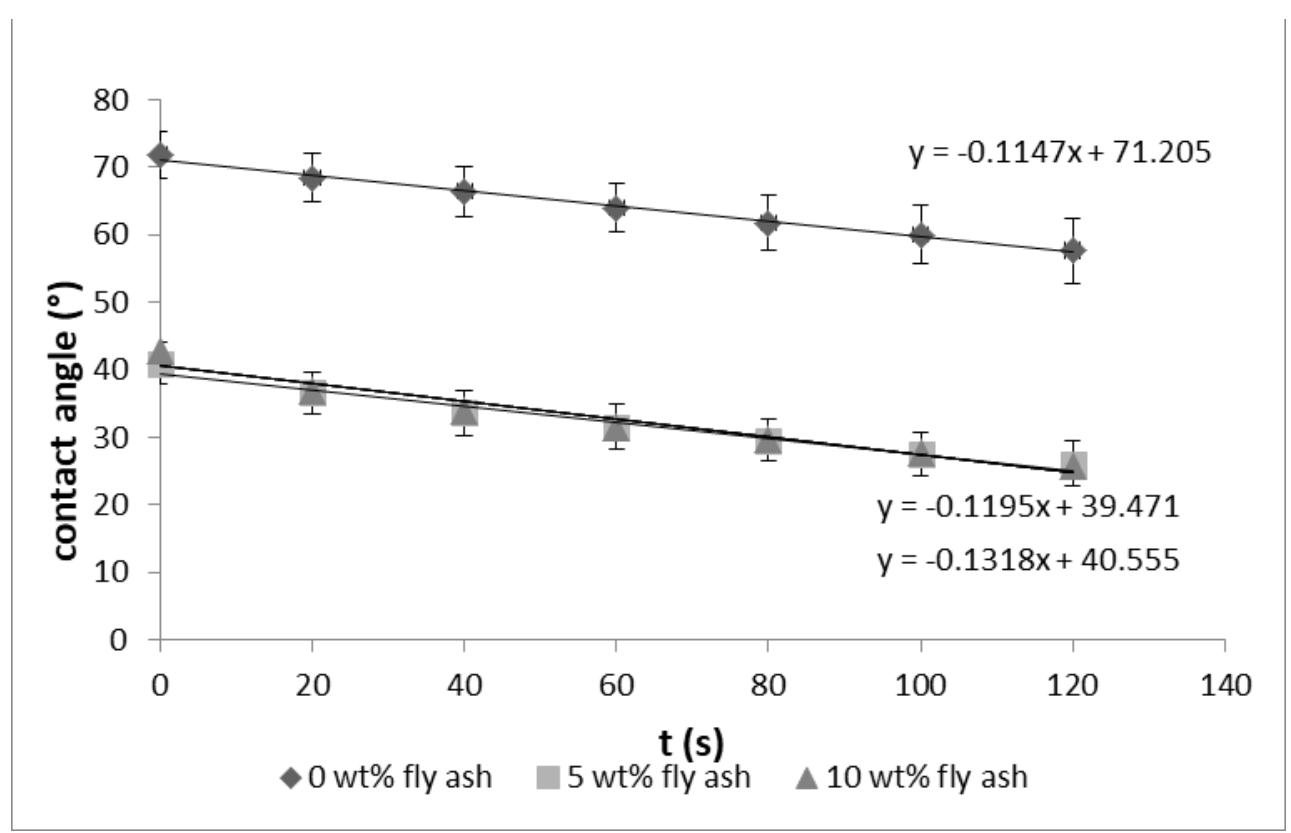

Figure 5. Wettability of compact geopolymer with and without high-carbon fly ash

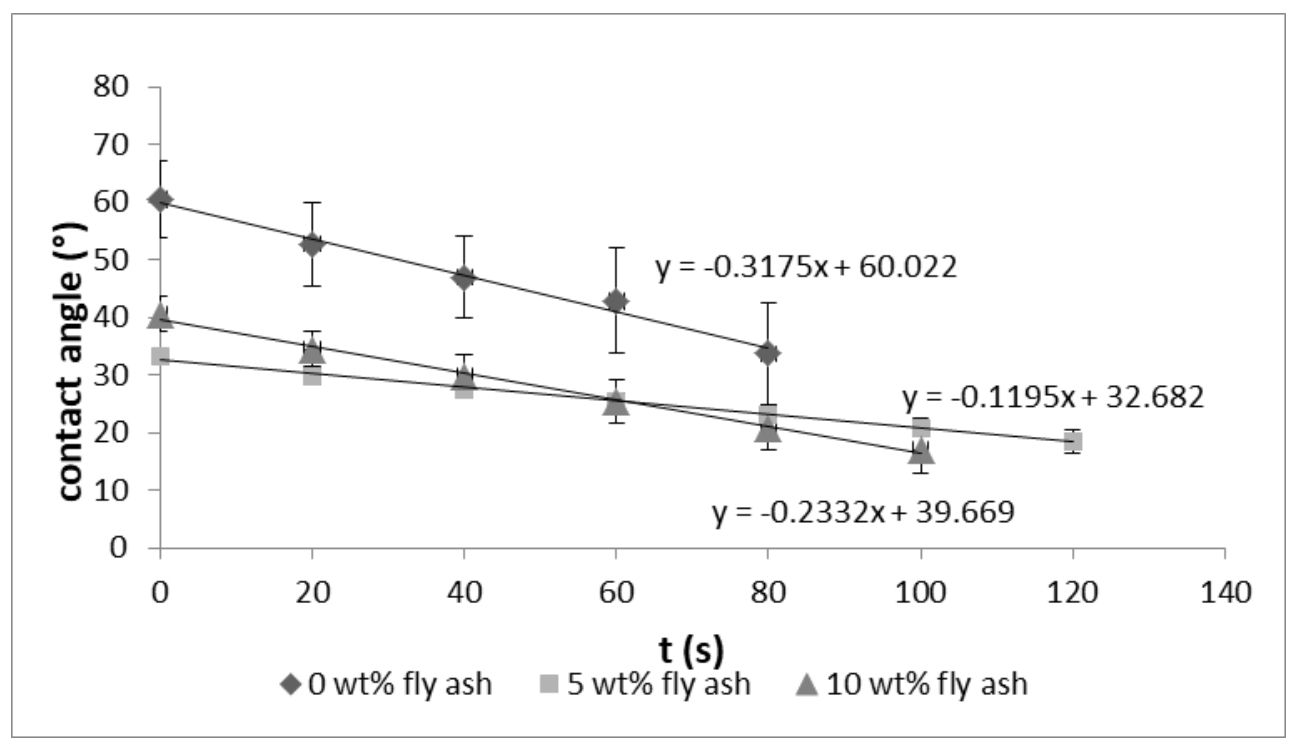

Figure 6. Wettability of foamed geopolymer with and without high-carbon fly ash

\subsection{Influence of potassium base}

Using potassium base significantly lowered initial contact angle and slightly increased soaking speed on compact samples, as seen in Fig. 7. Foamed potassium geopolymer, which foamed more significantly than the sodium one, could not be tested, as water completely soaked into its surface in a matter of seconds, unlike the foamed sodium geopolymer. 


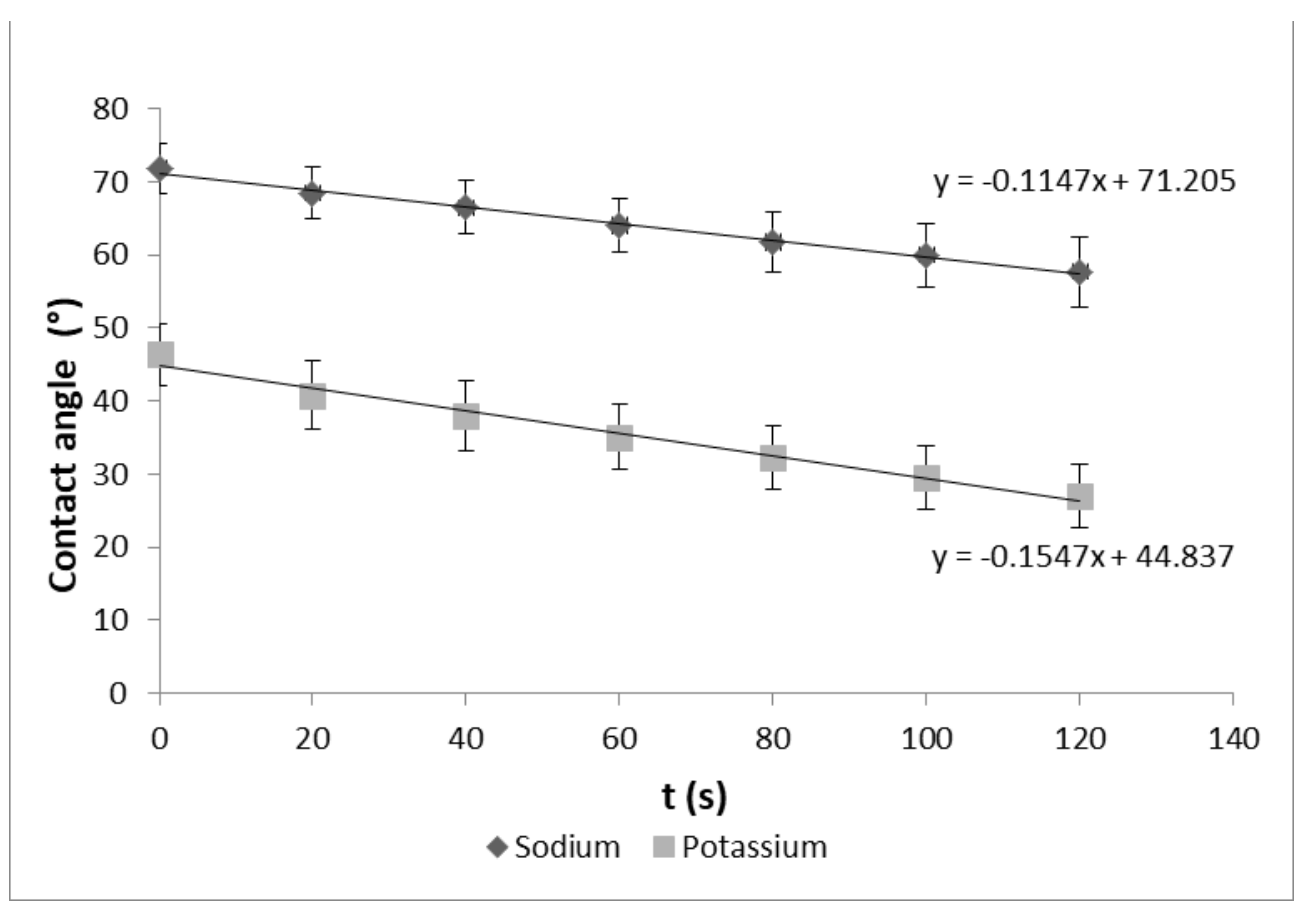

Figure 7. Wettability of compact geopolymer samples mader from sodium and potassium base

\subsection{Influence of plasma treatment on wettability}

Treating the geopolymer surface with CAP significantly increased its wettability, with water droplet soaking into the surface in less than 3 seconds. This result was the same for all samples, with plasma treated cut surface having highest wettability, as it was impossible to even measure the droplet on the surface, as it soaked in nearly instantly.

\subsection{Waterproofing}

Applying waterproofing varnish on geopolymer samples did prevent water from soaking into them, with the exception of foamed potassium based geopolymer, as it was impossible to properly coat it due to presence of large cavities. While the contact angle was still getting lower, it can be attributed to water evaporating, rather than soaking into the geopolymer, as the varnish produced uniform layer with no visible pores or cracks, there were no signs of water infiltration on geopolymer itself (surface darkening) and similar results being observed on microscope slide tested by the same method. The initial contact angles were also very similar and there vere no observable correlations between surface treatment or additive and the contact angle.

\section{Discussion}

In this paper, two main results were produced, first one determined the influence of various geopolymer ingredients on the wettability of resulting geopolymer composite, with the fly ash being the most influential ingredient, while the second one determined, and whether geopolymer surface treatment using low-energy, low-temperature atmospheric plasma makes the surface of geopolymers of various composition completely hydrophobic. As a secondary result, commercial waterproofing varnish was also tested on all geopolymer samples. 
While adding basalt fibers into the compact geopolymer increased its wettability slightly, as water soaked faster into its surface, adding it into foamed geopolymer decreased its wettability when compared to compact samples with fibers, up to the point of being nearly identical to compact samples without fibers. This can likely be attributed to basalt fibers influencing the foaming proces and formation of geopolymer surface.

For compact samples, high-carbon fly ash only lowered initial contact angle without speeding up soaking into the geopolymer, which might be helpful when treating geopolymer with water based solutions, as the wettability is higher. Adding fly ash into foamed geopolymers both lowered the initial contact angle and increase the speed of soaking of water into geopolymer. Once again, this is likely caused by fly ash influencing both the foaming process and surface formation.

For all samples, however, the changes were insignificant in the long term applications, such as when using geopolymer as construction material, as water eventually soaked into all of them (except those treated by waterproofing varnish) despite some of them being seemingly hydrophobic, as the initial contact angle was nearly $90^{\circ}$ during some measurements. All cut surfaces were highly wettable and soaked the water in almost immediately.

Geopolymer wettability was therefore influenced mostly by using fly ash and potassium base, with basalt fibers only having small impact on the wettability.

\subsection{Plasma activation and waterproofing}

Plasma activation was successful at making the geopolymer surface hydrophilic, regardless of additives. There are two possible explanations for this. Plasma may have changed the surface composition of the surface, as nitrogen plasma is known to nitride the surface by replacing oxygen with nitrogen [9], and deposited rective groups, such as hydroxil groups, on the surface, or changing the morphology of the surface by etching, as it is possible for plasma be used to etch surfaces, however, it usually requires heavier nonreactive elements, such as argon, to sputter away material from the surface without reacting with it, and CAP only contains roughly 1\% of Argon [10].

It is also possible to waterproof geopolymers by commercial varnishes, such as Revacryl UF 4210, which was successfully tested on geopolymer samples, with the exception of foamed potassium based geopolymer, as it foamed much more significantly than other samples and was impossible to coat properly due to cavities.

\section{Conclusion}

Multiple additives were tested for their influence on geopolymer wettability, while there were differences, none of them were significant, except for foamed potassium based geopolymer, which became completely hydrophobic. Using high-carbon fly ash does increase wettability of geopolymers, but doesn't speed up soaking of water into them. Commercial waterproofing varnish was successful at making all samples waterproof.

Cold atmospheric plasma was successful at activating the surface (both cut and uncut) of geopolymer and making it hydrophilic, and is therefore a viable method for pre-treatment of geopolymer surfaces before applying water-based varnishes or funcionalization solutions, although it was necessarary to use special systems for treating conductive surfaces.

In future studies, mechanism of hydrophilization of geopolymers should be investigated, as the effect may have been achieved either by changing the surface 
composition of geopolymer material, depositing reactive groups (such as hydroxil groups) or changing the morphology of the surface, as well as by combination of more changes. Influence of fly ash additives on mechanical properties of geopolymer should also be investigated.

\begin{abstract}
Author Contributions: Formal analysis, Vojtěch Růžek, Paweł Just and Przemysław Plaskota; Funding acquisition, Petr Louda; Investigation, Vojtěch Růžek; Project administration, Petr Louda; Resources, Vojtěch Růžek and Justyna Ciemnicka; Supervision, Petr Louda and Katarzyna Buczkowska; Visualization, Karol Prałat; Writing - original draft, Vojtěch Růžek; Writing - review \& editing, Vojtěch Růžek and Katarzyna Buczkowska..

Funding: This publication was written at the Technical University of Liberec, Faculty of Mechanical Engineering with the support of the Institutional Endowment for the Long Term Conceptual Development of Research Institutes, as provided by the Ministry of Education, Youth and Sports of the Czech Republic in the year 2021.
\end{abstract}

\begin{abstract}
Acknowledgments: This publication was written at the Technical University of Liberec, Faculty of Mechanical Engineering with the support of the Institutional Endowment for the Long Term Conceptual Development of Research Institutes, as provided by the Ministry of Education, Youth and Sports of the Czech Republic in the year 2021.

This work was supported by the Ministry of Education, Youth and Sports of the Czech Republic and the European Union - European Structural and Investment Funds in the frames of Operational Programme Research, Development and Education - project Hybrid Materials for Hierarchical Structures (HyHi, Reg. No. CZ.02.1.01/0.0/0.0/16_019/0000843).
\end{abstract}

Conflicts of Interest: The authors declare no conflict of interest.

\title{
References
}

1. Katarzyna, B.; Le, C.H.; Louda, P.; Michał, S.; Bakalova, T.; Tadeusz, P.; Prałat, K. The Fabrication of Geopolymer Foam Composites Incorporating Coke Dust Waste. Processes 2020, 8, 1052. https://doi.org/10.3390/pr8091052

2. Růžek, V. Vliv spalinových přiměsí a plazmatické úpravy na povrchové vlastnosti geopolymerů. Diploma thesis, Technical university of Liberec, 2020.

3. Yaghoubi, H. and N. Taghavinia, Surface chemistry of atmospheric plasma modified polycarbonate substrates. Applied Surface Science, 2011. 257(23): p. 9836-9839

4. Tendero, C., et al., Atmospheric pressure plasmas: A review. Spectrochimica Acta Part B: Atomic Spectroscopy, 2006. 61(1): p. 2-30.

5. Kowalonek, J., H. Kaczmarek, and A. Dąbrowska, Air plasma or UVirradiation applied to surface modification of pectin/poly(vinyl alcohol) blends. Applied Surface Science, 2010. 257(1): p. 325-331

6. Tesař, J. Plazmochemická aktivace povrchu skla v povrchovém výboji ve vzduchu za atmosférického tlaku. Bachelor thesis, Masaryk university, Brno, 2008.

7. Wang, J.H, 2012. 5.6.1 Plasma etching. Coatings for Biomedical Applications. s. 156- 157.

8. Baucis Lna. České lupkové závody a.s. Available online: https://www.cluz.cz/cz/baucis-lna (accessed on 17. 2.2021)

9. Seino, T., Matsuura, T. and Murota, J. (2002), Atomic-order nitridation of $\mathrm{SiO}_{2}$ by nitrogen plasma. Surf. Interface Anal., 34: 451-455.

10. Plasma etching https://www.plasma.com/en/applications/plasma-etching/ (accessed May 9, 2021).

11. Cold plasma from a single component https://www.tdk-electronics.tdk.com/en/373562/tech-library/articles/applications-cases/applications-cases/cold-plasma-fro m-a-single-component/1109546 (accessed January 12, 2022)

12. Kozub, B.; Bazan, P.; Mierzwiński, D.; Korniejenko, K. Fly-Ash-Based Geopolymers Reinforced by Melamine Fibers. Materials 2021, 14, 400. https://doi.org/10.3390/ma14020400

13. Gailitis, Rihards \& Sliseris, J. \& Korniejenko, Kinga \& Mikuła, Janusz \& Łach, Michał \& Pakrastins, Leonids \& Sprince, Andina. (2020). Long-Term Deformation Properties of a Carbon-Fiber-Reinforced Alkali-Activated Cement Composite. Mechanics of Composite Materials. 56. 10.1007/s11029-020-09862-w.

14. Korniejenko, Kinga \& Łach, Michał. (2020). Geopolymers reinforced by short and long fibres - innovative materials for additive manufacturing. Current Opinion in Chemical Engineering. 28. 167-172. 10.1016/j.coche.2020.06.005. 
15. Korniejenko, K.; Łach, M.; Chou, S.-Y.; Lin, W.-T.; Cheng, A.; Hebdowska-Krupa, M.; Gądek, S.; Mikuła, J. Mechanical Properties of Short Fiber-Reinforced Geopolymers Made by Casted and 3D Printing Methods: A Comparative Study. Materials 2020, 13, 579. https://doi.org/10.3390/ma13030579

16. Hiep Le Chi; Petr Louda; Su Le Van; Lukas Volesky; Vladimir Kovacic; Totka Bakalova. Composite Performance Evaluation of Basalt Textile-Reinforced Geopolymer Mortar. Fibers 2019, 7, 63 .

17. Chi Le; Petr Louda; Katarzyna Ewa Buczkowska; Iva Dufkova. Investigation on Flexural Behavior of Geopolymer-Based Carbon Textile/Basalt Fiber Hybrid Composite. Polymers 2021, 13, 751 .

18. Ciemnicka, J.; Prałat, K.; Koper, A.; Makomaski, G.; Majewski, Ł.; Wójcicka, K.; Buczkowska, K.E. Changes in the Strength Properties and Phase Transition of Gypsum Modified with Microspheres, Aerogel and HEMC Polymer. Materials 2021, 14, 3486. https://doi.org/10.3390/ma14133486

19. Taye, E.A.; Roether, J.A.; Schubert, D.W.; Redda, D.T.; Boccaccini, A.R. Hemp Fiber Reinforced Red Mud/Fly Ash Geopolymer Composite Materials: Effect of Fiber Content on Mechanical Strength. Materials 2021, 14, 511. https://doi.org/10.3390/ma14030511

20. Patrycja Bazan; Barbara Kozub; Kinga Korniejenko; Rihards Gailitis; Andina Sprince. Tribo-Mechanical Behavior of Geopolymer Composites with Wasted Flax Fibers. IOP Conference Series: Materials Science and Engineering 2021, 1190,012030 .

21. Barbara Kozub; Patrycja Bazan; Rihards Gailitis; Kinga Korniejenko; Dariusz Mierzwiński. Foamed Geopolymer Composites with the Addition of Glass Wool Waste. Materials 2021, 14, 4978 .

22. Rihards Gailīis; Andina Sprince; Leonids Pakrastins; Patrycja Bazan; Kinga Korniejenko. Plain and PVA fibre-reinforced geopolymer compact tension specimen critical area surface composition. Environment. Technology. Resources. Proceedings of the International Scientific and Practical Conference 2021, 3, 72 -77.

23. Gailitis, R.; Sprince, A.; Kozlovskis, T.; Radina, L.; Pakrastins, L.; Vatin, N. Long-Term Properties of Different Fiber Reinforcement Effect on Fly Ash-Based Geopolymer Composite. Crystals 2021, 11, 760. https://doi.org/10.3390/cryst11070760

24. Kinga Korniejenko; Dariusz Mierzwiński; Roland Szabó; Nóra Papné Halyag; Petr Louda; Eythor Rafn Thorhallsson; Gábor Mucsi. The impact of the curing process on the efflorescence and mechanical properties of basalt fibre reinforced fly ash-based geopolymer composites. MATEC Web of Conferences 2020, 322, 01004.

25. Kinga Korniejenko; Gábor Mucsi; Nóra Papné Halyag; Roland Szabó; Dariusz Mierzwiński; Petr Louda. Mechanical Properties of Basalt Fiber Reinforced Fly Ash-Based Geopolymer Composites. KnE Engineering 2020, 86-100 -86-100.

26. M Łach; M Hebdowska-Krupa; Dariusz Mierzwiński; Kinga Korniejenko. Mechanical properties of geopolymers reinforced with carbon and aramid long fibers. IOP Conference Series: Materials Science and Engineering 2019, 706, 012011.

27. Nguyen, V.V.; Le, V.S.; Louda, P.; Szczypiński, M.M.; Ercoli, R.; Vojtěch, R.; Łoś, P.; Prałat, K.; Plaskota, P.; Pacyniak, T.; Buczkowska, K.E. Low-Density Geopolymer Composites for the Construction Industry. Polymers 2022, $14,304$. https://doi.org/10.3390/polym14020304

28. Van Su Le; Michal M. Szczypinski; Pavlína Hájková; Vladimir Kovacic; Totka Bakalova; Lukas Volesky; Le Chi Hiep; Petr Louda. Mechanical properties of geopolymer foam at high temperature. Science and Engineering of Composite Materials 2020, 27, $129-138$.

29. Van Su Le; Petr Louda; Huu Nam Tran; Phu Dong Nguyen; Totka Bakalova; Katarzyna Ewa Buczkowska; Iva Dufkova. Study on Temperature-Dependent Properties and Fire Resistance of Metakaolin-Based Geopolymer Foams. Polymers 2020, 12, 2994 .

30. Van Su Le; Petr Louda. Research of Curing Time and Temperature-Dependent Strengths and Fire Resistance of Geopolymer Foam Coated on an Aluminum Plate. Coatings 2021, 11, 87 .

31. Prałat, K.; Ciemnicka, J.; Koper, A.; Buczkowska, K.E.; Łoś, P. Comparison of the Thermal Properties of Geopolymer and Modified Gypsum. Polymers 2021, 13, 1220. https://doi.org/10.3390/polym13081220

32. Rihards Gailitis; Kinga Korniejenko; Andina Sprince; Leonids Pakrastins. Comparison of the long-term properties of foamed concrete and geopolymer concrete in compression. 3 rd National conference on current and emerging process technologies - Concept 2020 2020, 2239, 020012.

33. Mária Ambrus; Roland Szabó; Gábor Mucsi; Ambrus M.; Szabó R.; Mucsi G.. Utilisation and Quality Management of Power Plant Fly Ash. International Journal of Engineering and Management Sciences 2019, 4, 329 -337.

34. Quyen V. Trinh; Gábor Mucsi; Thai V. Dang; Ly P. Le; Van H. Bui; Sándor Nagy. The influence of process conditions on ground coal slag and blast furnace slag based geopolymer properties. Rudarsko-geološko-naftni zbornik 2020, 35, 15 -20.

35. Ferenc Kristály; Roland Szabó; Ferenc Mádai; Ákos Debreczeni; Gábor Mucsi. Lightweight composite from fly ash geopolymer and glass foam. Journal of Sustainable Cement-Based Materials 2020, 10, 1 -22.

36. Kinga Korniejenko; Michał Łach; Janusz Mikuła; Maria Hebdowska-Krupa; Dariusz Mierzwiński; Szymon Gądek; Marek Hebda. Development of 3D Printing Technology for Geopolymers. XV International Conference on Durability of Building Materials and Components. eBook of Proceedings 2020, 1 .

37. Michał Łach; Dariusz Mierzwiński; Kinga Korniejenko; Janusz Mikuła. Geopolymer foam as a passive fire protection. MATEC Web of Conferences 2018, 247, 00031

38. Volokhova, A.A.; Fedorishin, D.A.; Khvastunova, A.O.; Spiridonova, T.I.; Kozelskaya, A.I.; Kzhyshkowska, J.; Tverdokhlebov, S.I.; Kurzina, I. Reactive Magnetron Plasma Modification of Electrospun PLLA Scaffolds with Incorporated Chloramphenicol for Controlled Drug Release. Polymers 2022, 14, 373. https://doi.org/10.3390/polym14030373 
39. Volokhova, A.A.; Fedorishin, D.A.; Khvastunova, A.O.; Spiridonova, T.I.; Kozelskaya, A.I.; Kzhyshkowska, J.; Tverdokhlebov, S.I.; Kurzina, I. Reactive Magnetron Plasma Modification of Electrospun PLLA Scaffolds with Incorporated Chloramphenicol for Controlled Drug Release. Polymers 2022, 14, 373. https://doi.org/10.3390/polym14030373

40. Hiep Le Chi; Pavlína Hájková; Su Le Van; Petr Louda; Lukáš Voleský. Water Absorption Properties of Geopolymer Foam after Being Impregnated with Hydrophobic Agents. Materials 2019, 12, 4162 .

41. Revacryl ${ }^{\mathrm{TM}}$ Ultrafine 4210 Technical sheet,

https://www.synthomer.com/fileadmin/files/tds/REVACRYL\%20ULTRAFINE\%204210\%20(Coatings).pdf/ (accessed January 16, 2022). 